\title{
A NARRATIVIDADE DA MORTE DE QASEM SOLEIMANI A PARTIR DO TEXTO NÃO VERBAL FOTOGRÁFICO NA IMPRENSA
}

\section{THE NARRATIVITY OF THE DEATH OF QASEM SOLEIMANI FROM THE PHOTOGRAPHIC NONVERBAL TEXT IN THE PRESS}

\author{
Felipe Gonçalves Carneiro ${ }^{67}$ \\ João de Deus Leite ${ }^{68}$
}

\begin{abstract}
RESUMO
Neste artigo, propomo-nos a analisar o funcionamento discursivo do texto não verbal fotográfico do acontecimento discursivo-jornalístico da morte de Qasem Soleimani, que circulou na imprensa nacional e internacional, quando da divulgação da morte de Qasem Soleimani. Trata-se de pensar, antes de tudo, na narratividade que é construída em diferentes portais de notícias sobre o acontecimento discursivo-jornalístico da morte de Soleimani. Para tanto, filiamo-nos ao campo epistemológico da Análise de Discurso francesa, preconizada por Michel Pêcheux, a partir da qual mobilizamos noções de arquivo, de memória e de mídia, como aparelho de poder, uma vez que a materialidade fotográfica que nos interessa teve circulação na imprensa. Em nossas considerações analíticas, construímos (im)possíveis sentidos a partir do texto não verbal fotográfico, considerando-o em sua eficácia simbólica, sem a sobreposição da linguagem verbal. Ademais, problematizamos o seu reducionismo e a movência de sentidos, quando ele está sob os efeitos do regime enunciativo midiático. Observamos que a mídia, como gerenciadora de arquivos, (re)produz e legitima sentidos de que os EUA são uma nação invencível. As discursividades imperialistas, capitalistas e do poderio bélico estadunidense se inscrevem na materialidade linguística da parafrasagem do texto não verbal fotográfico.
\end{abstract}

\section{PALAVRAS-CHAVE}

Análise de Discurso; Texto não verbal fotográfico; Qasem Soleimani.

\begin{abstract}
In this article, we propose to analyze the discursive functioning of the photographic nonverbal text of the discursive-journalistic event of Qasem Soleimani's death, that circulated in the national and international press, when the death of Qasem Soleimani was announced. It is about thinking, above all, about that narrativity that is built in different news portals about discursive-journalistic event of Qasem Soleimani's death. Therefore, we join the epistemological field of French Discourse Analysis, advocated by Michel Pêcheux, from which we mobilized notions of file, memory and media, as a power device, because the photographic materiality that interests us had circulation in the press. In our analytical considerations, we construct (im)possible meanings from the photographic nonverbal text, considering it in its symbolic effectiveness, without the overlapping of verbal language. Furthermore, we problematized its reductionism and the movement of meanings, when it is under the effects of the media enunciative regime. We note that the media, as an archive manager, (re)produces and legitimizes meanings that United States are invincible nation. Imperialist, capitalist and US military power discursivities are inscribed in the linguistic materiality of the paraphrase of the photographic nonverbal text.
\end{abstract}

67 Mestrando em Letras: Ensino de Língua e Literatura, Universidade Federal do Tocantins: felipegcarneiro@yahoo.com.br.

${ }^{68}$ Doutor em Estudos Linguísticos, Universidade Federal do Tocantins (UFT), Campus de Araguaína: joaodedeusleite@hotmail.com. 


\section{KEYWORDS}

Discourse Analysis; Photographic nonverbal text; Qasem Soleimani.

\section{INTRODUÇÃO}

No início de 2020, mais precisamente no dia 03 de janeiro, a mídia brasileira e estrangeira noticiaram o acontecimento da morte do major-general Qasem Soleimani, responsável por ações militares e estratégicas do Irã. Conforme noticiado na imprensa, a autoria do ataque ao militar iraniano, que ocorreu na cidade de Bagdá, no Iraque, foi assumida pelos Estados Unidos, sob a autorização do presidente estadunidense. A partir daí, por um lado, (re)inicia-se uma tensão entre os estados-nações envolvidos na referida situação. Por outro, esse (novo) momento de tensão acarretou em preocupações por parte da comunidade internacional, mobilizando-se em ações, no campo diplomático, para estabelecer a diminuição e o apaziguamento da situação apreensiva que, a partir de então, irrompeu-se entre a esses dois países. Dada as condições que culminaram no evento que citamos, pairouse certo temor de que o acontecimento em si pudesse se tornar em gatilho para um conflito bélico de proporções maiores e incalculáveis na região do Oriente Médio.

Com efeito, em face do acontecimento que tratamos de sumarizar no parágrafo anterior, e a sua propagação na esfera jornalística, fomos motivados a arvorar alguns questionamentos acerca do engendramento de sentidos, considerando-o, como acontecimento discursivo (PÊCHEUX, 2015[1983]). Entendemos que os sentidos de toda e qualquer materialidade simbólica se constituem na e pela historicidade, e cumpre considerar que, a depender do plano de circulação (ORLANDI, 2001), outros contornos de significância são-lhe imputados ao objeto simbólico. Assim, a nossa reflexão incide sobre o acontecimento jornalístico $^{69}$ (DELA-SILVA; DIAS, 2015) de Qasem Soleimani, na maneira pela qual se constituiu a sua discursivização na e pela imprensa. Nessa medida, ocupar-nos-emos em problematizar e analisar a materialidade significante fotográfica que foi veiculada na esfera jornalística, tanto nacional quanto estrangeira, dando-lhe um efeito de evidência à

\footnotetext{
${ }^{69} \mathrm{O}$ artigo de Dela-Silva e Dias (2015, p. 126) nos esclarece que "o discurso jornalístico recorta aquilo que é considerado relevante, alçando-o à condição de acontecimento jornalístico”.
} 
materialidade visual do acontecimento discursivo-jornalístico que, neste artigo, estamos circunstanciando.

Sob a égide da Análise de Discurso de matriz francesa (AD, doravante), preconizada pelo filósofo Michel Pêcheux, buscamos apreender o funcionamento discursivo do texto não verbal fotográfico atrelado ao acontecimento discursivo-jornalístico da morte do militar iraniano Qasem Soleimani, que teve circulação na mídia em vários países. Ao pensarmos em nosso material de análise, partimos do pressuposto axiomático do campo epistemológico pêcheuxtiano de que a linguagem é opaca, cuja não transparência da materialidade abre espaço para o equívoco. A memória discursiva é acionada e se (re)atualiza no corpo do simbólico (intradiscurso). Assim, com tal perspectiva, somos contrários à ideia de univocidade da significação.

No caso do intercorrido entre os Estados Unidos e o Irã, observamos que, dada as condições de produção, sentidos outros são possíveis de engendramento na articulação do simbólico com a historicidade. Dessa forma, tendo em vista a conjuntura em questão, há um acirramento de sentidos, em que se estabelece nas sociedades estadunidenses e nas iranianas uma divisão desigual de sentidos. Eles recebem contornos de evidência e de transparência a partir de sua inscrição em formações discursivas dominantes, as quais estão sob o domínio complexo das formações ideológicas (PÊCHEUX, 2014[1975]). Contudo, partindo da maquinaria discursiva e concebendo a instabilidade das formações discursivas, na (re)elaboração da teoria a qual nos filiamos, é dada à memória contornos de acentuação. No complexo funcionamento da ideologia no processo de interpelação dos sujeitos, há que "tensionada pela memória, a FD [formação discursiva] incorpora, cada vez mais, a instabilidade e a dispersão dos sentidos que são radicalizados no último texto de Pêcheux (...)" (GREGOLIN, 2005, s/p).

Dessa forma, com vistas ao que estamos ponderando a respeito do evento sucedido nos primeiros dias de 2020, e em consonância com as considerações teóricas que vimos incursionando, compreendemos que a depender da constituição sócio-histórica e 
ideológica dos sujeitos, decorre a construção de narratividades ${ }^{70}$ frente ao acontecimento discursivo-jornalístico da morte de Qasem Soleimani. Nesse sentido, buscando apresentar um alicerçamento teórico que sustente o nosso artigo, apresentamos, na seção intitulada " $\mathrm{O}$ arquivo, a mídia e a leitura do texto não verbal fotográfico", o nosso recorte no âmbito do território epistemológico pêcheuxtiano que nos auxiliará com a problematização à qual nos centramos.

Em atenção ao nosso material de análise que elegemos para este artigo, tendo em vista a incompletude constitutiva do texto não verbal fotográfico, cuja espessura semântica abre espaço para a dispersão de sentidos, ocupar-nos-emos em problematizar e analisar em que medida a fotografia do acontecimento discursivo-jornalístico da morte do militar Qasem Soleimani, com circulação na imprensa nacional e internacional, aporta para a construção de narratividades. É necessário ressaltar que a materialidade visual fotográfica é parafraseada pela linguagem verbal, acarretando no reducionismo de sua significância (ORLANDI, 1995; MONNERAT, 2013; SOUZA, 2001; 2011). Nessa medida, de acordo com Carneiro e Leite (2020), o texto não verbal fotográfico na mídia é assepsiada por meio do regime enunciativo midiático, em que a verbalização da materialidade simbólica fotográfica (nesse caso, o título e o subtítulo da notícia), veiculada na imprensa, enclausura sentidos outros que são (im)possíveis de serem engendrados. Em outras palavras, há não-ditos (invisíveis) na fotografia que produzem significação. Assim, depreendemos que a materialidade simbólica fotográfica é o lugar do (im)possível que vai além do cerceamento de sentidos dados pelo regime enunciativo midiático (CARNEIRO; LEITE, 2020).

Consoante com as questões circunstanciadas, neste artigo, e sob a esteira teóricometodológica da $\mathrm{AD}$, elegemos como material de análise três notícias veiculadas em sites jornalísticos, cujo mesmo texto não verbal fotográfico teve circulação on-line no âmbito dessas reportagens, noticiando o ataque estadunidense que acarretou na morte do militar Qasem Soleimani, em que tomamo-la como acontecimento discursivo-jornalístico. Em nossas considerações analíticas, as quais estão inseridas na seção intitulada como "A

${ }^{70}$ Orlandi (2016, p. 13) define "narratividade como a maneira pela qual uma memória se diz em processos identitários, apoiados em modos de individuação do sujeito, afirmando/vinculando seu pertencimento a espaços de interpretação determinado, consoantes a específicas práticas discursivas”. 
narratividade da morte de Qasem Soleimani na imprensa", centramo-nos em analisar, discursivamente, a materialidade fotográfica com a elisão do texto verbal, considerando-a como prática discursiva ${ }^{71}$, bem como sob os efeitos prisionais (im)postos pelos regimes enunciativos midiáticos dessas três notícias as quais foram recortados para $\mathrm{o}$ desenvolvimento deste artigo.

Assim, no batimento das materialidades verbal e não verbal do nosso corpus, queremos saber em que medida o texto não verbal fotográfico veiculado na imprensa nacional e estrangeira implica a construção de narratividade do acontecimento discursivo-jornalístico de Qasem Soleimani, militar iraniano morto em janeiro de 2020.

\section{O ARQUIVO, A MÍDIA E A LEITURA DO TEXTO NÃO VERBAL FOTOGRÁFICO}

Nesta seção, assentados na perspectiva teórico-metodológica da AD pêcheuxtiana, apresentamos o nosso recorte teórico, com o intuito de construirmos as incursões teóricas que nos deram base para problematizar e analisar o texto não verbal fotográfico, que teve imensa circulação e difusão nos noticiários brasileiros e estrangeiros, conforme já ressaltamos anteriormente. Inicialmente, mobilizamos questões concernentes ao arquivo, em que alinhavamos com as redes de memória e os seus efeitos no engendramento de sentidos e, por conseguinte, tendo implicações na leitura-interpretação da materialidade significante fotográfica em questão, bem como na construção de narratividades. Na sequência, considerando os objetivos traçados para este artigo, articulamos esses dispositivos teórico-metodológicos com a questão da circulação do nosso objeto simbólico na esfera jornalística (mídia). Justificamos a nossa incursão por este percurso teórico aqui delineado, uma vez que o texto não verbal fotográfico de nosso interesse analítico teve sua circulação na imprensa, sendo ele então passível de ser (re)significado.

Courtine (2006, p. 2), em consonância com o campo da AD e cujas palavras as mobilizamos em nosso artigo, enfatiza que "a memória que nos interessa aqui é a memória

\footnotetext{
${ }^{71}$ De acordo com Orlandi (1995, p. 46), “a noção de prática discursiva permite que se estenda a reflexão sobre os processo de produção de sentidos sem o efeito da dominância do verbal, já que por ela não trabalhamos mais com textos mas com práticas discursivas (sejam verbais ou não)".
} 
social, coletiva, em sua relação com a linguagem e a história”. Nessa asserção, temos a memória e suas decorrências no processo de engendramento de sentidos, ou seja, sentidos estes que se historicizam. Nessa perspectiva, refletimos sobre texto não verbal fotográfico, como objeto simbólico. Dessa forma, a partir da superfície de sua materialidade significante, coadunamos com a premissa de que a sua "linguagem é o tecido da memória, isto é, sua modalidade de existência histórica essencial" (COURTINE, 2006, p. 10). Assim, inferimos que a materialidade visual fotográfica do acontecimento discursivo-jornalístico da morte do militar iraniano possui, em sua superfície textual, considerada como forma de linguagem, operadores discursivos não verbais (SOUZA, 2001) capazes de (re)atualização de memória(s). Dando sequência aos nossos apontamentos, citamos um excerto de Souza (2001, p. 81) que vai ao encontro da temática que vimos trazendo. A autora articula arquivo, memória e imagem, vejamos as suas considerações:

Há um Arquivo, cuja forma de inscrição pressupõe uma memória armazenada e institucionalizada na e pela imagem. Não são discurso apenas os textos verbais e orais; também a cestaria, a cerâmica, a pintura corporal, a dança, o traçado organizador da aldeia, a sonoridade das palavras, da música, são formas de discursividade que, quando analisadas em sua relação com a instituição, favorecem compreender como o trabalho da memória histórica gera a memória discursiva nessas sociedades (SOUZA, 2001, p. 81, grifos nossos).

Segundo o fragmento que mencionamos anteriormente, as materialidades não verbais são alçadas à categoria de discurso, definido por Pêcheux (2014[1969], p. 81) como “efeito de sentidos”. Esse alçamento significa dizer que o texto não verbal fotográfico é tomado como materialidade significante do discurso. Dessa forma, podemos corroborar que, a partir do texto visual fotográfico, memória(s) institucionalizada(s) socialmente é(são) acionada(s). Ademais, Mittmann (2014, p. 36) acentua que "materialidade histórica e materialidade linguística e imagética (entre outras) constituem os documentos de arquivo". A partir dessa compreensão, permitimo-nos em arvorar reflexões no tocante ao arquivo (memória), bem como à mídia, dado que o texto não verbal fotográfico da morte de Qasem Soleimani foi discursivizado na e pela imprensa.

Pêcheux (2014[1982]), em seu texto Ler o arquivo hoje, alicerçado nos fundamentos na disciplina interpretativa por ele (re)elaborada, com a qual caminha na contra- 
direção da transparência da linguagem, traz na época à discussão alguns apontamentos concernentes ao procedimento da prática de leitura do arquivo textual. Nesse texto, ele pontua de maneira genérica o arquivo como sendo "campo de documentos pertinentes e disponíveis sobre uma questão" (PÊCHEUX, 2014[1982], p. 59), sendo que o arquivo é, "por sua leitura, revelador de interesses históricos, políticos e culturais" (SARGENTINI, 2014, p. 25). Nesse sentido, prossegue-se que na leitura do arquivo textual, no contexto do processo de tratamento de textos, "os aparelhos do poder de nossas sociedades gerem, a memória coletiva" (PÊCHEUX, 2014[1982], p. 59).

Com base nos pontos levantados no referido processo de leitura do arquivo, decorrem indubitavelmente inferências interpretativas, gerando efeitos de literalidade (sentido único) que são mantidos, efetuando-se na construção de uma memória social. Esse efeito de unicidade na (re)produção dos sentidos, na leitura do arquivo, promove a seu turno determinados apagamentos de significância. Assim, entendemos a alusão de Pêcheux (2014[1982], p. 59) a respeito da assertiva que diz: "um espaço polêmico das maneiras de ler [o arquivo]" (acréscimo nosso em colchetes), considerando o panorama de que se apaga a plurivocidade de sentidos da materialidade linguístico-histórica. Para ele, "é esta relação entre língua como sistema sintático intrinsecamente passível de jogo, e a discursividade como inscrição de efeitos linguísticos materiais na história, que constitui o nó central de um trabalho de leitura de arquivo" (PÊCHEUX, 2014[1982], p. 66, grifos do autor).

Seguindo com as nossas reflexões, apresentamos um trecho do texto Ler o arquivo hoje, segundo Pêcheux (2014[1982], p. 59 e 60):

A outra vertente da leitura de arquivo - sem a qual a primeira não existiria provavelmente como tal - tem aderências históricas completamente diferentes: trata-se desse enorme trabalho anônimo, fastidioso, mas necessário, através do qual os aparelhos do poder de nossas sociedades gerem a memória coletiva. Desde a Idade Média a divisão começou no meio dos clérigos, entre alguns deles, autorizados a ler, falar e escrever em seus nomes (logo, portadores de uma leitura e de uma obra própria) e o conjunto de todos os outros, cujos gestos incansavelmente repetidos (de cópia, transcrição, extração, classificação, indexação, codificação etc.) constituem também uma leitura, mas uma leitura impondo ao sujeito-leitor seu apagamento atrás da instituição que o emprega: o grande número de escrivães, copistas e "contínuos", particulares e públicos, constituiu-se, através da Era Clássica e até nossos dias, sobre esta renúncia a toda pretensão de "originalidade", sobre este apagamento de si na prática silenciosa de uma leitura consagrada ao serviço de uma Igreja, de um rei, de um Estado, ou de uma empresa (PÊCHEUX, 2014[1982], p. 59 e 60, grifos do autor). 
Na medida em que mobilizamos, ao nosso recorte teórico, essas considerações arvoradas por Pêcheux em 1982, somos instigados a refletir a respeito da mídia, como aparelho de poder e em suas implicações no tratamento textual e no gerenciamento de memória social (DELA-SILVA; DIAS, 2015), uma vez que:

o arquivo pode ser considerado como fonte porque é a esse conjunto de saberes que o sujeito recorre para poder enunciar. Com isso, pode se dizer que o arquivo discursivo embasa o dizer, sendo um repositório de sentidos regulado pela memória, que seleciona o que permanece ou não arquivado. A memória, afetada pela regularização e desregularização acionada pela absorção dos acontecimentos que irrompem, escolhe quais sentidos devem ser lembrados ou esquecidos (LAMPOGLIA; ROMÃO, 2011, p. 35-36).

Dessa forma, inserimos na pauta de nossas reflexões os seguintes questionamentos, vejamos: de que modo o arquivo na mídia, considerando-a como aparelho de poder, e nesse sentido, (re)produtora de uma memória coletiva e social, resvala sobre o que vimos pontuando neste artigo, na relação de engendramento de sentidos entre os Estados Unidos e o Oriente Médio, mais precisamente com o Irã? E mais: em que medida o texto não verbal fotográfico veiculado na imprensa o qual discursiviza o acontecimento discursivojornalístico da morte de Qasem Soleimani, aciona redes de memória, (re)atualizando sentidos e implicado (im)possíveis leituras-interpretações que, por sua vez, abarcam a construção de certa narratividade?

Mittmann (2014, p. 33) salienta que "sem dúvida, o modo de circulação faz significar de maneira particular os documentos de arquivo". À luz dessa consideração, reportamo-nos à mídia, como (re)produtora e gerenciadora de arquivo (aparelho de poder), em que promove a circulação e a (re)produção textos (verbais e/ou não verbais) com sentidos já legitimados acerca dos Estados Unidos, do Irã e dos demais países do Oriente Médio. Diante disso, entendemos que determinados sentidos são estabilizados, na medida em que outros são apagados. Por consequência, "promovendo gestos de interpretação, dizendo como esses fatos devem ser interpretados, ou seja, que efeitos de sentidos estão autorizados a (re)produzir" (DELA-SILVA; DIAS, 2015, p. 126). Em deferência à circulação de sentidos nos suportes midiáticos, Gregolin $(2003$, p. 96) pontua a seguinte asserção, com a qual 
podemos notar o desempenho fulcral da mídia no acionamento de sentidos, tal como o seu funcionamento como arquivo. Observemos:

\begin{abstract}
Podemos iniciar a exploração de tantas e tão complexas questões pela constatação de que a mídia produz sentido por meio de um insistente retorno de figuras, de sínteses-narrativas, de representações que constituem o imaginário social. Fazendo circular essas figuras, ela constrói uma "história do presente", simulando acontecimentos-em-curso que vêm eivados de signos do passado. Se analisarmos o funcionamento discursivo da mídia, poderemos entrever esses movimentos de resgate de memória e de estabelecimento do imaginário de uma identidade social (GREGOLIN, 2003, p. 96, grifos nossos).
\end{abstract}

Neste ponto, em atenção aos objetivos traçados para a composição desta seção, vamos buscar alinhavar os assentamentos teóricos mobilizados até então com o texto não verbal fotográfico, cuja circulação se dá na e pela mídia jornalística. Conforme já dissemos, a materialidade imagética fotográfica veiculada na esfera jornalística é parafraseada pela linguagem verbal. Neste caso, referimo-nos à materialidade linguística da reportagem jornalística, circunscrita no título e no subtítulo, em que o material significante fotográfico está atrelado, denominado como regime enunciativo midiático (CARNEIRO; LEITE, 2020).

O texto imagético fotográfico, considerando-o como "contingência pura" (BARTHES, 2015[1980], p. 31), fornece assim evidências materiais (visuais) de comprovação do acontecimento. Contudo, a incompletude do texto não verbal fotográfico, como prática discursiva, é de tal ordem que a sua estrutura visual-textual mantém-se sujeita ao equívoco e à falha. Desse modo, observamos que, devido à sua circulação na mídia, a materialidade fotográfica em conjunção com o verbal sofre um reducionismo de sua eficácia simbólica. Vemos em operação o suposto efeito de completude que é (im)posto pelo regime enunciativo midiático agenciados pelos "aparelhos de poder". E mais: ressaltamos que esses trajetos de leitura no discurso jornalístico estão sob os comandos de "certas regras internas e externas da instituição midiática" (BARBOSA, 2003, p. 113). De nossa perspectiva teórica, tanto regime enunciativo midiático quanto o texto não verbal fotográfico, tomando-os como materialidades simbólicas significantes, constituem os documentos de arquivo na mídia, sendo capazes de acionamento de memória social.

Dada as considerações arroladas até o presente momento, em que nos propusemos a articular as questões alusivas ao arquivo, à mídia e ao texto não verbal 
fotográfico, convém-nos salientar que não há sobreposição justa nem encaixe perfeito da materialidade verbal com a não verbal fotográfica, isto é, há uma suposta relação imaginária de biunivocidade (significante linguístico e significante imagético em justaposição). $\mathrm{O}$ deslize e o deslocamento de sentidos se fazem presentes. Assim, do mesmo modo que se opera o efeito do interdiscurso (já-dito) no linguístico, há (não)ditos e (in)visíveis nos significantes materiais. Entendemos que ambas as materialidades de linguagem, com a inscrição na historicidade, acionam redes de memória concebendo-lhe ao corpo material (im)possíveis sentidos.

A parafrasagem do texto não verbal fotográfico vinculada na imprensa é nada mais que o fenômeno de discursivização da materialidade imagética, efetuado pelo regime enunciativo midiático, dando-lhe contornos de transparência e de evidência do sentido, ou seja, concernindo univocidade à fotografia. Sob a nossa perspectiva teórica, entendemos que o sentido formulado pelo parafraseamento é oriundo da inscrição e da identificação do sujeito-autor-jornalista em uma formação discursiva dominante. Esse fenômeno se opera por meio do assujeitamento à ideologia, porquanto as formações discursivas "representam 'na linguagem' as formações ideológicas que lhes são correspondentes" (PÊCHEUX, 2014[1975], p. 147, aspas do autor). Nas palavras de Orlandi (2012, p. 78):

\footnotetext{
A formação discursiva é, enfim, o lugar da constituição do sentido e da identificação do sujeito. É nela que todo sujeito se reconhece (em sua relação consigo mesmo e com outros sujeitos) e aí está a condição do famoso consenso intersubjetivo (a evidência de que eu e tu somos sujeitos) em que, ao se identificar, o sujeito adquire identidade (Pêcheux, 1975). É nela também, como dissemos, que o sentido adquire sua unidade (ORLANDI, 2012, p. 78).
}

Assim, é na formação discursiva que o texto não verbal fotográfico da morte do iraniano Qasem Soleimani é significado. Contudo, a unidade e a dispersão têm ubicação na materialidade. A própria formação discursiva é marcada por uma instabilidade, cuja fronteira limítrofe não é de um engessamento marcado que separa um interior e um exterior, mas, sim, "se inscreve entre diversas FD [formações discursivas] como uma fronteira se desloca em função das questões de luta ideológica", sendo esse deslocamento regulado pelo interdiscurso (memória) (COURTINE; MARANDIN, 2016, p. 39, grifo dos autores). Vejamos, na passagem que segue abaixo, o funcionamento do interdiscurso na formação discursiva: 


\begin{abstract}
Em função dos pontos críticos que acabam de ser introduzidos, diremos que o interdiscurso consiste em um processo de reconfiguração incessante no qual uma FD [formação discursiva] é levada, em função das posições ideológicas que essa FD represente em uma conjuntura determinada, a incorporar elementos préconstruídos produzidos no seu exterior, para nela produzir a redefinição ou o retorno, para igualmente evocar seus próprios elementos, para organizar sua repetição, mas também para provocar nela o apagamento, o esquecimento ou mesmo a denegação (COURTINE; MARANDIN, 2016, p. 39-40, grifo dos autores).
\end{abstract}

Neste momento, para apreender o funcionamento discursivo do texto não verbal fotográfico, como prática discursiva, afastá-lo-emos do recobrimento do verbal, uma vez que a imagem fotográfica da morte do iraniano Qasem Soleimani teve circulação na imprensa. Segundo Souza (2011. p. 79), "a mídia, muitas vezes, trabalha com a redução do não verbal ao verbal, dando lugar a um efeito de transparência, de objetividade da informação". Ainda com o concurso da autora, apoiar-nos-emos em seu conceito de policromia (SOUZA, 2001; 2011; 2018), definido como "rede de elementos visuais, implícitos ou silenciados" (SOUZA, 2011, p. 390). Por meio dessa perspectiva teórica, é-nos possível elencar operadores discursivos não verbais na superfície textual da imagem que aportam no engendramento de significações. Isso posto, "a cor, o detalhe, o ângulo da câmera, um elemento da paisagem, luz e sombra, etc., os quais não só trabalham a textualidade da imagem, como instauram a produção de outros textos, todos não verbais" (SOUZA, 2001, p. 81). Ao tratar da imagem fotográfica, Souza $(2011 ; 2018)$ se apoia, na esteira de Barthes (2015[1980]), e apresentanos os conceitos de studium e de punctum. Diferenciam-se na medida em que o primeiro está sob a intencionalidade do fotógrafo na captura da imagem; já o segundo está a cargo do olharleitor do espectador da fotografia. Na perspectiva discursiva, Souza (2011) esclarece que:

o punctum como um traço de textualidade inerente ao caráter de incompletude da fotografia. O punctum se define como algo casual, fugaz, por isso mesmo tem relação com a memória, como interdiscurso, porque abre à interpretação. A partir do punctum, há toda uma instituição de dizeres, que nos remete à atualização da memória face ao sentido instituído pelo esquecimento (SOUZA, 2011, p. 389).

Dando continuidade à compreensão dos processos de produção de sentido na materialidade imagética, convidamos Courtine $(2011 ; 2013)$ e seus apontamentos sobre a análise de imagens e memória. Ele afirma que “da mesma forma que existe o 'sempre já' do discurso, existe o sempre já da imagem" (COURTINE, 2013, p. 156, grifos do autor). Temos 
a noção de intericonicidade, assentado na perspectiva arqueológica foucaultiana, a qual consiste em uma complexa relação entre imagens, porque supõe "a relação entre imagens externas, mas também entre imagens internas, as imagens de lembrança, as imagens de rememoração, as imagens das impressões visuais armazenadas pelo indivíduo" (COURTINE, 2011, p. 160). Ainda segundo o autor, a partir de uma imagem, remetemo-la a outras já existentes, já vistas ou imaginadas. Nesse sentido, observamos que:

uma fotografia, portanto, nunca está verdadeiramente isolada: ela é comparável às formas pré-construídas do discurso e, como elas, ela pode ser citada, convocada, evocada, e igualmente e evidentemente apagada... Dito outramente: a fotografia constitui um dos quadros sociais essenciais da memória contemporânea, um dos suportes ao mesmo tempo material e físico da cultura visual de nossas sociedades (COURTINE, 2013, p. 157).

Agora, ponderando acerca da proposição de nosso artigo, esperamos que as implicações conceituais aqui construídas ao longo desta seção, no tocante ao arquivo, à mídia e à leitura do texto não verbal fotográfico, ajudem-nos na leitura-interpretação da materialidade significante fotográfica vinculada ao acontecimento discursivo-jornalístico da morte de militar Qasem Soleimani em circulação na imprensa, assim como nos desdobramentos para a construção de narratividades. Na seção subsequente, encontram-se as nossas considerações analíticas concernentes ao que problematizamos.

\section{A NARRATIVIDADE DA MORTE DE QASEM SOLEIMANI NA IMPRENSA}

Conforme vimos elencando ao longo do artigo, as nossas considerações analíticas se assentam na problematização e na análise do texto não verbal fotográfico da morte de Qasem Soleimani, que teve grande circulação na imprensa, na medida em que ele constrói narratividades do acontecimento em questão. Dessa forma, nesta seção, com o objetivo de atingir os fins a que nos propomos, realizamos gestos de interpretação com ancoragem na materialidade significante fotográfica. Em face de sua inserção na prática discursiva jornalística, analisamos os efeitos de sentido engendrados pelo objeto simbólico fotográfico sob os efeitos prisionais (im)postos pelo regime enunciativo midiático, assim como analisamo-lo com a elisão do texto verbal da imprensa. Embasados em nossa perspectiva teórico-metodológica, a narratividade da morte de Qasem Soleimani se dá em termos de 
efeitos de sentido produzidos frente à materialidade significante fotográfica veiculada na imprensa.

Para a seleção de nosso material de análise, seguimos alguns procedimentos os quais apresentamos a seguir. Dado o nosso interesse analítico de problematizar e de analisar o texto não verbal fotográfico veiculado na imprensa, elegemos três reportagens na internet de jornais que noticiaram a morte do militar iraniano. De acordo com o que foi noticiado amplamente na imprensa nacional e internacional, no terceiro dia de janeiro de 2020, ocorreu um ataque militar dos Estados Unidos em Bagdá, no Iraque, por volta de uma da manhã, horário local, que resultou no fato que vimos circunstanciando. Segundo as informações da imprensa, a investida militar estadunidense teve lugar nas proximidades do aeroporto internacional da capital iraquiana, e o ataque aéreo norte-americano atingiu o automóvel que conduzia a vítima. Na madrugada desse dia, jornalistas obtiveram o registro fotográfico do veículo destroçado e em chamas. A imagem fotográfica teve circulação na e pela imprensa, dando autenticidade e contundência ao evento.

Nesse sentido, o texto não verbal fotográfico da morte de Qasem Soleimani, dando veracidade ao ocorrido e com circulação na esfera jornalística, torna-se o nosso objeto de problematização e de análise. À luz disso, interessamo-nos por reportagens que apresentavam como ponto central a imagem fotográfica do acidente, a qual apresentamos em seguida (Figura 1). 


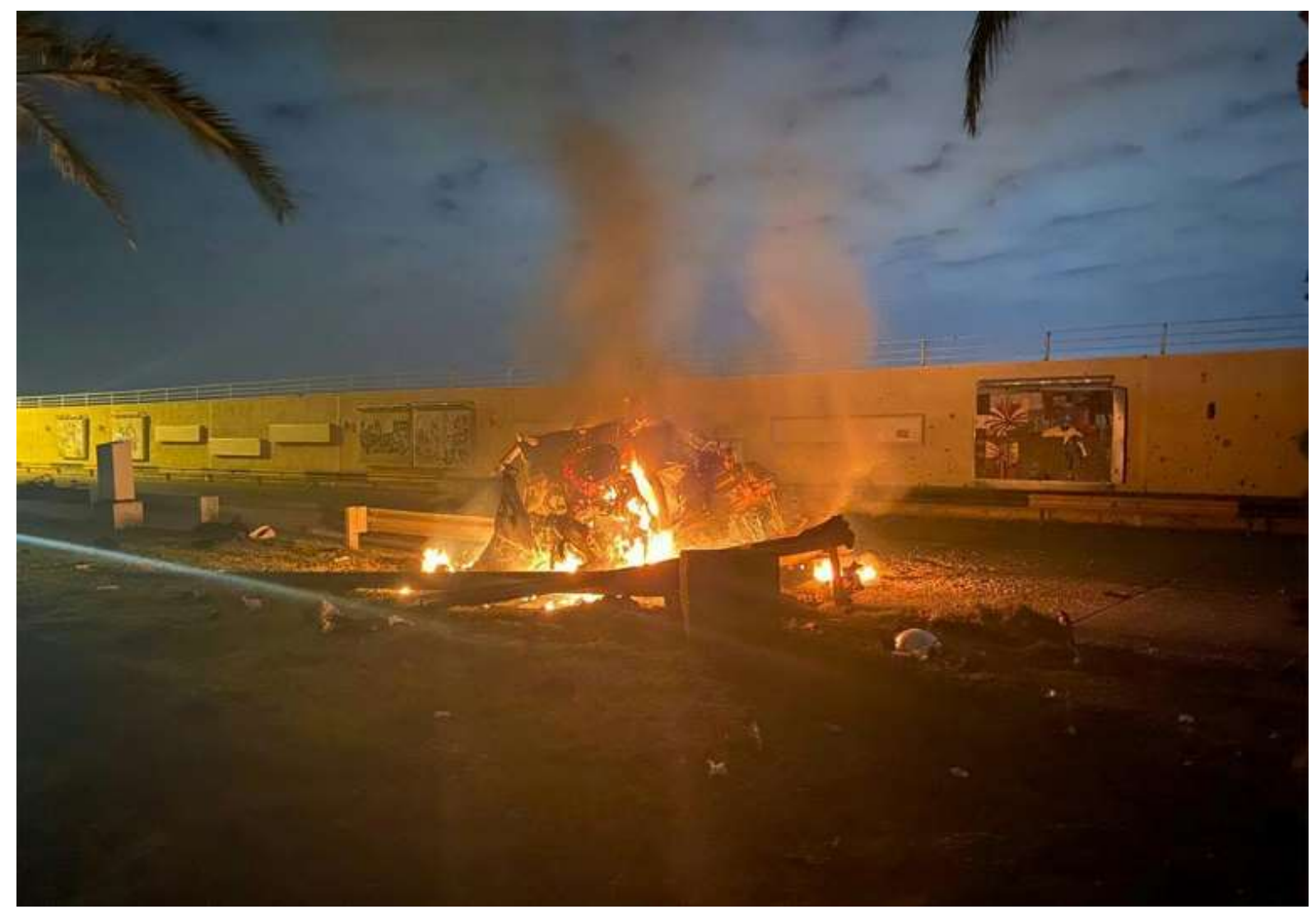

Figura 1 - Texto não verbal fotográfico da morte de Qasem Soleimani, que ocorreu no dia 03 de janeiro de 2020. Fonte: site de notícias Isto é. ${ }^{72}$

Realizamos uma pesquisa por imagens no buscador Google para a seleção de reportagens que atendessem aos requisitos que delimitamos. Enfocamos notícias datadas próximas ao dia 03 de janeiro; ademais descartamos aquelas que apareciam a foto do militar iraniano na centralidade da reportagem e/ou que tivessem outras imagens sendo usadas como base para noticiar o acontecimento. Enfim, não nos interessamos por páginas web que não tivessem a materialidade fotográfica de nosso interesse. As três reportagens eleitas para o nosso artigo possuem a mesma imagem fotográfica do acontecimento de janeiro de 2020 , e ela está na centralidade das três notícias, atendendo, assim, à nossa proposição.

72 Disponível em: https://istoe.com.br/morte-de-soleimani-foi-operacao-sem-precedentes-para-exercitodos-eua/. Acesso em 21 de janeiro de 2020. 
Coadunamos com a teorização de que o texto não verbal fotográfico significa, cuja incompletude se marca na medida em que se abrem espaços para infindáveis leituras, em sua relação com a historicidade. Entretanto, quando esse material fotográfico está em circulação na imprensa, ele é assepsiado pela linguagem verbal, ou seja, é discursivizado com marcas de filiações a formações ideológicas. Nessa medida, recortamos para análise do funcionamento discursivo, além da materialidade significante fotográfica (Figura 1), os regimes enunciativos midiáticos (título e subtítulo) correlacionados a ela.

A seguir, apresentamos uma tabela (Tabela 1) com os regimes enunciativos midiáticos (REM, doravante) eleitos de reportagens que foram acessadas na internet. Esses recortes, em conjunção com o texto não verbal fotográfico, compõem o nosso material de análise. No total, são três notícias para o escopo de nossas considerações analíticas, a saber: uma do Brasil, oriunda do site da Isto É; uma em inglês, proveniente do site de notícias do jornal The New York Times; e uma da BBC Español. Vejamos a tabela:

Tabela 1 - Parafrasagem do texto não verbal fotográfico da morte de Qasem Soleimani veiculada da imprensa (REM).

\begin{tabular}{lr|l}
\hline $\begin{array}{l}\text { Veículo de } \\
\text { imprensa e data de } \\
\text { publicação }\end{array}$ & Regime enunciativo midiático (REM) \\
\hline $\begin{array}{l}\text { Isto é } \\
\text { 03/01/2020 }\end{array}$ & $\begin{array}{l}\text { (REM 1): "Morte de Soleimani foi operação sem precedentes para o } \\
\text { exérito dos EUA". 73 }\end{array}$ \\
\hline $\begin{array}{l}\text { The New York } \\
\text { Times }\end{array}$ & $\begin{array}{l}\text { (REM 2): “U.S. Strike in Iraq Kills Qassim Suleimani, Commander of } \\
02 / 01 / 2020\end{array}$ & \begin{tabular}{l} 
Iranian Forces" \\
\hline
\end{tabular}
\end{tabular}

73 Disponível em: https://istoe.com.br/morte-de-soleimani-foi-operacao-sem-precedentespara-exercito-dos-eual. Acesso em 21 de janeiro de 2020. 


\begin{tabular}{|c|c|}
\hline & $\begin{array}{l}\text { "Suleimani was planning attacks on Americans across the region, } \\
\text { leading to airstrike in Baghdad, the Pentagon statement said. Iran's } \\
\text { supreme leader called for vengeance". } 74 \\
\text { Tradução nossa: } \\
\text { "Ataque americano no Iraque mata Qasem Soleimani, Comandante das } \\
\text { Forças Iranianas". } \\
\text { "Soleimani estava planejando ataques contra americanos em toda a } \\
\text { região, comandando ataques aéreos em Bagdá, disse declaração do } \\
\text { Pentágono. O líder supremo do Irã pediu vingança". }\end{array}$ \\
\hline $\begin{array}{l}\text { BBC Español } \\
03 / 01 / 2020\end{array}$ & $\begin{array}{l}\text { (REM 3): "Muerte de Qasem Soleimani: cómo fue el 'ataque de } \\
\text { precisión' en el que EE.UU. eliminó el militar más poderoso de Irán (y } \\
\text { qué hay detrás)". }{ }^{75} \\
\text { Tradução nossa: } \\
\text { "Morte de Qasem Soleimani: como foi o 'ataque de precisão' em que os } \\
\text { EUA eliminaram o militar mais poderoso do Irã (e o que há por trás)". }\end{array}$ \\
\hline
\end{tabular}

Fonte: Sites Isto é, The New York Times e BBC Español.

A interpretação de toda e qualquer materialidade, sendo verbal ou não verbal, é isenta de neutralidade. $\mathrm{O}$ engendramento de sentidos se dá por meio do complexo mecanismo de assujeitamento ideológico, na relação de identificação do sujeito-interpretante com a ideologia que o interpela. Nesse sentido, observamos que tampouco há neutralidade nos

74 Disponível em: https://www.nytimes.com/2020/01/02/world/middleeast/qassem-soleimani-iraq-iranattack.html. Acesso em 21 de janeiro de 2020.

${ }^{75}$ Disponível em: https://www.bbc.com/mundo/noticias-internacional-50989553. Acesso em 21 de janeiro de 2020 
REMs que parafraseiam e discursivizam as materialidades significantes fotográficas, dandolhes um trajeto de leitura, no qual promove um efeito de transparência de sentido, quando elas estão veiculadas na imprensa.

No plano central do texto não verbal fotográfico, em que configuramos como o studium da materialidade visual, divisamos a intencionalidade do sujeito-fotógrafo, que objetivou o registro em si da tragédia. Nesse âmbito intencional, observamos uma (possível) estrutura automotiva que está em chamas. Considerando que o fogo está flamejando e há fumaça sobre a estrutura destroçada e retorcida, podemos inferir que a imagem registra e flagra um acontecimento recente, pese ao fato de que não logramos essa precisão na descrição da imagem, apenas conjecturamos. No dito (visível) da imagem, tem-se um (possível) acidente automobilístico. Para nós, essa possibilidade se dá na medida em que associamos os destroços da materialidade fotográfica a um automóvel, devido à presença de traços na imagem que caracterizam uma autopista (asfalto, barra de proteção metálica etc.). Então, se considerarmos que foi um acidente automobilístico, questionamo-nos: aconteceu entre quantos carros? Foi apenas um veículo envolvido no acidente?

Nesse sentido, abrimos para alguns espaços de interpretação, a saber: considerando a quantidade de acidentes de aeronaves, no Brasil, é passível de interpretação que os destroços remontam à imagem de um acidente com uma aeronave de pequeno porte que caiu na zona urbana, por exemplo. Uma memória discursiva é passível de ser acionada e atualizada em um sujeito-interpretante que resida em uma região com alto registro de acidentes dessa natureza, temos, então, a presença do "sempre já da imagem" (COURTINE, 2013). O invisível (não dito) da imagem, significando na materialidade simbólica fotográfica, atesta a sua incompletude. E mais: podemos atrelar as labaredas dos destroços que se apresentam no visível do material fotográfico à ação de criminosos sob o comando de milícias e/ou de narcotraficantes que atuam na ilegalidade nos grandes centros urbanos. Em decorrência disso, podemos concatenar a imagem do fogaréu à queima de automóveis, ou mesmo de ônibus, em resposta à ação ostensiva da polícia na repressão de crimes. Além do mais, suponhamos que uma criança visse esse texto visual, e em face de sua constituição sócio-histórica e ideológica, podemos hipotetizar que, para ela, no dito (visível) da fotografia era a queda de um meteoro ou nave espacial. 
Na superfície textual da fotografia, chama-nos a atenção ao fato de que não há no campo do visível da imagem a presença de vítimas do acidente. Não vemos corpos nem viaturas de ambulância, tampouco policiamento etc. Caso tenha havido vítimas fatais, está no invisível (não dito) do texto imagético, porque podemos pressupor que um acidente automobilístico dessa natureza, sem sombra de dúvidas, ninguém sairia ileso. É possível, igualmente, efetuar gestos de interpretação para esse quesito construído, vejamos: será que no acidente as vítimas (ou a vítima, pois não sabemos o quantitativo de pessoas envolvidas no acidente) foram resgatadas com vida e, em seguida, após o salvamento, o carro começou a incendiar-se? Não há corpos no plano da imagem fotográfica porque o condutor (e demais possíveis passageiros) foi (foram) arremessado(s) para fora do veículo, e o automóvel seguiu ainda o trajeto linear até parar na localidade específica apresentada pela fotografia. Notamos que infindáveis leituras são possíveis no texto não verbal fotográfico. Múltiplas são as narrativas construídas com ancoragem somente no imagético. A memória discursiva perpassa pela materialidade do texto não verbal fotográfico. A significância se mostra contínua, sempre em movimento. Agora, façamo-nos uma pergunta retórica: em que medida podemos fazer uma conjunção desse texto não verbal fotográfico, sem o parafraseamento do verbal, à morte de Qasem Soleimani, ou aos Estados Unidos, ou ao Irã, ou ao Oriente Médio?

Em nosso mo(vi)mento de análise discursiva da materialidade visual, pudemos divisar a heterogeneidade e a opacidade que a constitui. Contudo, com a circulação da materialidade fotográfica na esfera jornalística, a sua eficácia simbólica é reduzida em face ao trajeto de leitura que lhe é imputada. Fornece-lhe contornos de homogeneidade e de unidade, como se houvesse um único sentido possível. Nessa perspectiva, o texto não verbal fotográfico se apresenta como lugar de contradição, uma vez que redes de memórias podem ser acionadas e em certa medida produzir efeitos de sentido que diferem do direcionamento (im)posto pelo REM.

A nosso ver, considerando que a tônica central da imagem fotográfica é a (possível) estrutura automobilística em chamas, observamos que o falecimento de Qasem Soleimani se localiza no campo da pressuposição. Com o efeito do imaginário, vemos em funcionamento os REMs recobrindo a materialidade fotográfica. Vemos como a verbalização participa da construção de sentidos, ou seja, o que estava no campo da pressuposição desloca- 
se para o posto da fotografia, com delineamento de obviedade. Corroboramos que os seguintes recortes: no REM1, temos o enunciado "Morte de Soleimani”; já no REM2, "mata Qasem Soleimani”, e no terceiro, encontramos "Morte de Qasem Soleimani”. O sentido desloca-se a partir dos REMs. Em virtude desse apontamento, podemos, por exemplo, antever um corpo (ou corpos) carbonizado dentro das ferragens, nos destroços do possível veículo em chamas. A localização de Qasem Soleimani na fotografia só foi possível a partir dos REMs. Cumpre-nos acentuar que há o apagamento de possíveis outras vítimas. Houve somente o militar Soleimani como vítima fatal nesse acidente? Tanto na materialidade fotográfica quanto na materialidade linguística dos REMs, notamos a invisibilidade de demais vítimas fatais. Nesse ponto, a narratividade do acontecimento discursivo-jornalístico recai somente na figura do militar iraniano. Quais motivos de se invisibilizar as demais vítimas desse evento? Quem é (foi) Qasem Soleimani e o que ele representa(va)? Dado que ele foi a única vítima identificada pela linguagem verbal, há o pressuposto de tratar-se de uma figura eminente. Essas interrogações, as quais arvoramos para discussão, foram articuladas aos recortes dos REMs, bem como a seus efeitos para a construção da narratividade. A figura de Soleimani ganha contornos de identificação e de significação com os seguintes trechos: "comandante das Forças Iranianas" (REM2) e "o militar mais poderoso do Irã" (REM3). A partir dessa seleção, depreendemos tratar-se de indivíduo de considerável notoriedade para o Irã, bem como para os EUA. Eis a possível razão pela qual a sua visibilidade ser marca nos REMs citados e o apagamento das demais supostas vítimas do ataque norte-americano.

No REM1, trazemos para as nossas considerações analíticas o recorte "operação sem precedentes para o exército dos EUA". Nesse caso, observamos a adjetivação do substantivo "operação" por "sem precedentes". Pela dicionarização, a expressão adjetival é significada como algo singular, inimaginável, que jamais havia acontecido, enfim, como se não houvesse outro registro dessa feitura. Nesse sentido, há uma valoração da "operação" dos Estados Unidos. Discursiviza-se o poderio bélico estadunidense. Essa discursivização mostra-se visível no texto não verbal fotográfico na medida em que vemos os destroços em chamas do possível automóvel. Contudo, a locução "sem precedentes" também gera o efeito de algo foi levado a cabo sem critério, sem anterioridade, isto é, sem motivo plausível que justificasse tal feito. Vemos em funcionamento uma contradição na materialidade linguística 
do REM1. Embora tenha sido com razões prévias ou não, de igual modo, vemos discursivizada a potencialidade bélica do exército norte-americano. Dessa forma, vemos a mídia (re)atualizar memórias em que apresentam Tio Sam como invencível.

No REM1, observamos somente a presença do sintagma "EUA" que marca território/nacionalidade. No REM2, apresenta-se, como inscrição linguística material, mais nacionalidades e localidades, vejamos: "Ataque americano no Iraque", "Comandante das Forças Iranianas", "Ataque aéreos em Bagdá", "líder supremo do Irã", grifos nossos. De nossa perspectiva, entendemos que essas informações estão no âmbito do invisível no texto não verbal fotográfico. O REM2 promove sentidos diversos a partir dos significantes linguísticos que acentuamos. Entendemos que, com base neles, produz-se um efeito nas redes de memórias, o qual propicia narratividades acerca dos Estados Unidos, do Irã, bem como da região do Oriente Médio. Assim, o que se encontrava na invisibilidade da imagem recebem trajetos e delimitações de certos efeitos de sentido sobre a materialidade visual. Observamos, por conseguinte, um efeito espacial-territorial no corpo da materialidade não verbal fotográfica. Uma memória discursiva de conflitos na região do Oriente Médio é mobilizada.

Outro ponto que queremos evidenciar é que, no REM2, há a justificativa para tal acontecimento, que se marca no trecho: "Soleimani estava planejando ataques contra americanos (...)”. Em dissonância com o REM1 que mobilizamos um diferente efeito para o enunciado adjetival "sem precedentes", aqui, no REM2, a culpabilidade do ataque recai sobre o próprio Qasem Soleimani e o governo iraniano. Entretanto, podemos instigar a seguinte pergunta: "Qual a veracidade desse fato, dessa informação, em que se justifica o ataque militar?". Eis que encontramos, no REM2, um enunciado, a saber: “disse declaração do Pentágono". Para nós, esse enunciado legitima a veracidade da informação que ganha caução a partir do imaginário do que o Pentágono, instituição militar norte-americana, representa discursivamente. Novamente, certo poderio bélico estadunidense é discursivizado. E, igualmente, a potencialidade bélica estadunidense se marca na materialidade da fotografia.

No REM3, ao contrário do REM2, não há indícios da motivação do ataque que culminou na morte de Qasem Soleimani. Entretanto, assim como nos demais REM, o terceiro também discursiviza o potencial bélico ("ataque de precisão"). Constrói-se e reforça o sentido de que os EUA são uma nação invencível. Com tal perspectiva, vemos que a mídia, como 
gerenciadora de arquivo, (re)produz e endossa esse sentido. A narratividade de nação invencível se inscreve na superfície da materialidade fotográfica na medida em que divisamos os destroços do possível automóvel em chamas. E mais: podemos destacar que, neste REM3, a discursividade imperialista e a capitalista se marcam na materialidade linguístico-histórica “e o que há por trás?”. Nesse ponto, notamos que a justificativa não se baseia em algo vinculado à autodefesa dos EUA, como observamos no REM2, em que culpabilizava o militar Soleimani pela sua própria morte, bem como o governo iraniano. Há uma pressuposição de filiação a ideologias que possuem como cerne interesses puramente econômicos.

\section{CONSIDERAÇÕES FINAIS}

No decorrer deste artigo, filiados à perspectiva discursiva da Análise de Discurso de Michel Pêcheux, problematizamos e analisamos três reportagens veiculadas em sites jornalísticos que discorriam acerca do ataque estadunidense que acarretou na morte do militar Qasem Soleimani. As reportagens eleitas para as nossas considerações analíticas possuíam como ponto de ancoragem da notícia o texto não verbal fotográfico do acontecimento discursivo-jornalístico. Entendemos que a materialidade fotográfica em circulação na mídia engendra um efeito de veracidade do fato em si, como também produz um efeito de unidade na reportagem a qual está ela inserida. Contudo, apartamo-nos da perspectiva que concebe a ideia de univocidade da significação. Os sentidos são moventes, e eles se dão com o acionamento da memória discursiva que perpassa pela materialidade significante, ou seja, no corpo do intradiscurso.

Mobilizamos, em nosso recorte teórico, dispositivos que nos auxiliassem a lançar um olhar-discursivo ao texto não verbal fotográfico em circulação da mídia. Nesse sentido, apoiamo-nos em questões concernentes ao arquivo, à memória e à mídia. A partir de nossas análises, inferimos que a mídia, como aparelho de poder, promove a circulação e a (re)produção de sentidos, segundo os quais os Estados Unidos são detentores de um potencial bélico, conferindo-lhes um efeito de invencibilidade. Tais redes de memórias ganham mobilidade a partir da materialidade fotográfica em circulação na imprensa, e aportam para a construção de narratividade acerca da morte de Qasem Soleimani. 
Ao centrarmos no funcionamento discursivo do texto não verbal fotográfico, pudemos enfatizar a sua propriedade opaca. A partir da materialidade visual, inferimos múltiplas leituras. Assim sendo, o nosso objeto simbólico fotográfico torna-se um lugar de contradição e de dispersão de sentidos. Ressaltamos que a morte do militar iraniano está no campo da pressuposição da fotografia, considerando que não havia traços de corpos (vítimas) na superfície do imagético. E mais: de posse somente da materialidade fotográfica, observamos que a autoria do ataque (EUA), a localidade (Bagdá, Iraque) e as vítimas (Qasem Soleimani e governo iraniano) estão no campo do não dito (invisível) do texto não verbal.

Os nossos apontamentos analíticos também versaram sobre os regimes enunciativos midiáticos (REM) que verbalizaram a fotografia. $\mathrm{O}$ efeito do verbal sobre o não verbal é de tal ordem que determinados sentidos são (im)postos, configurando em trajetos de leitura e reduzindo a sua capacidade de simbolização. O texto não verbal fotográfico é discursivizado na imprensa. Assim sendo, observamos que sentidos que estavam no âmbito do não dito (invisível) da imagem deslocaram-se a tal ponto que obtiveram visibilidade na discursivização, em decorrência de efeitos produzidos a partir dos REMs. As discursividades imperialista, capitalista e do potencial bélico estadunidense foram inscritas nas materialidades linguísticas dos REMs analisados.

Observamos que os diferentes recobrimentos do texto não verbal fotográfico, mesmo que haja um reducionismo de sua força simbólica, atestam incompletude da materialidade visual fotográfica. A própria imagem estabelece pontos de deriva e de dispersão dos sentidos, e a sua circulação na imprensa aporta para diferentes narratividades acerca da morte de Qasem Soleimani.

\section{REFERÊNCIAS}

BARBOSA, Pedro Luis Navarro. O papel da imagem e da memória na escrita jornalística da história do tempo presente. In: GREGOLIN, Maria do Rosário (Org.). Discurso e mídia: a cultura do espetáculo. São Carlos: Claraluz, 2003, p. 111-124.

BARTHES, Roland. A câmara clara: nota sobre a fotografia. Tradução Júlio Castañon Guimarães. - [ed. especial] - Rio de Janeiro: Nova Fronteira, 2015 [1980]. 
CARNEIRO, Felipe Gonçalves; LEITE, João de Deus. O regime enunciativo midiático e a memória discursiva na disputa de sentidos no texto não verbal fotográfico. Falange Miúda. v. 5 , n. 1, 2020, p. 78-93.

COURTINE, Jean-Jacques; MARANDIN, Jean Marie. Que objeto para a Análise de Discurso. In: CONEIN, Bernard; COURTINE, Jean-Jacques; GADET, Françoise; MARANDIN, Jean Marie; PÊCHEUX, Michel (Orgs.). Materialidades Discursivas. Campinas, SP: Editora da Unicamp, 2016.

COURTINE, Jean-Jacques. Decifrar o corpo: pensar com Foucault. Tradução de Francisco Morás. Petrópolis, RJ: Vozes, 2013.

COURTINE, Jean-Jacques. Discurso e imagens: para uma arqueologia do imaginário. In: PIOVEZANI, Carlos; CURCINO, Luzmara; SARGENTINI, Vanice (Org.). Discurso, Semiologia e História. São Carlos: Claraluz, 2011.

O tecido da memória: algumas perspectivas de trabalho histórico nas ciências da linguagem. Polifonia. Cuiabá, v. 12, n. 2, 2006, p. 1-13.

DELA-SILVA, Silmara; DIAS, Jucilene Pereira. Felicidade, um arquivo. Sobre a noção de arquivo e o seu funcionamento no discurso da/na mídia. In: Análise do Discurso: dos fundamentos aos desdobramentos (30 anos de Michel Pêcheux). INDURSKY, Freda; FERREIRA, Maria Cristina Leandro, MITTMANN, Solange. Campinas, SP: Mercado das Letras, 2015.

GREGOLIN, Maria do Rosário. Formação discursiva, redes de memória e trajetos sociais de sentido: mídia e produção de identidade [online]. Disponível em: 
https://moodle.ufsc.br/pluginfile.php/1867818/mod_resource/content/1/Gregolin_Formacao _discursiva_redes_de_memoria.pdf. Acesso em 21 de jan. 2020.

. O acontecimento discursivo na mídia: metáfora de uma breve história do tempo. In: GREGOLIN, Maria do Rosário (Org.). Discurso e mídia: a cultura do espetáculo. São Carlos: Claraluz, 2003, p. 95-110.

LAMPOGLIA, Francis; ROMÃO, Lucília Maria Sousa. Memória e arquivo no discurso jornalístico: a anistia em revista. Cadernos de Linguagem e Sociedade. 12 (1), 2011, p. $30-48$.

MITTMANN, Solange. Formação discursiva e autoria na produção e na circulação de arquivos. Conexão das Letras. Porto Alegre, v. 9, n 11, 2014, p. 31-40.

MONNERAT, Rosane. A imagem no discurso publicitário: texto verbal e não verbal podem estar em conflito? In: MENDES. Emília; MACHADO, Ida Lucia; LIMA, Helcira; LYSARDO-DIAS, Dylia (Org.). Imagem e discurso. Belo Horizonte: FALE/UFMG, 2013, p. 406-425.

ORLANDI, Eni Puccinelli. Discurso e Leitura. 9a ed. - São Paulo: Cortez, 2012.

. Efeitos do verbal sobre o não-verbal. Rua, Campinas, Labeurb, Nudecri, n. 1, p. 3547, 1995.

Discurso e Texto: formação e circulação dos sentidos. Campinas, SP: Pontes, 2001.

. (Org.). Instituição, relatos e lendas: narratividade e individuação dos sujeitos. Pouso Alegre: Univás; Campinas: RG Editores, 2016. 
PÊCHEUX, Michel. Ler o arquivo hoje. In: ORLANDI, Eni Puccinelli (Org.) [et al.]. Gestos de Leitura. $4^{\text {a }}$ ed. Campinas, SP: Editora da Unicamp, 2014 [1982].

PÊCHEUX, Michel. O discurso: estrutura ou acontecimento? Campinas, SP: Pontes Editores, 2015 [1983].

Por uma análise automática do discurso: uma introdução à obra de Michel Pêcheux / Organizadores Françoise Gadet; Tony Hak; tradução Bethania S. Mariani... [et al.] - 5 a ed. Campinas, SP: Editora da Unicamp, 2014 [1969].

. Semântica e discurso: uma crítica à afirmação do obvio / Michel Pêcheux; tradução: Eni Puccinelli Orlandi et al. $-5^{\mathrm{a}}$ ed. Campinas, SP: Editora da Unicamp, 2014 [1975].

SARGENTINI, Vanice Maria Oliveira. O arquivo e a circulação de sentidos. Conexão das Letras. Porto Alegre, v. 9, n 11, 2014, p. 23-30.

SOUZA, Tânia Conceição Clemente de. Perspectivas da análise do (in)visível: a arquitetura discursiva do não verbal. Rua, Campinas-SP, v. 24, n. 1, p. 17-35, jun. 2018.

A análise do não verbal e os usos da imagem nos meios de comunicação. Rua, Campinas: 7, p. 65-94, 2001.

Imagem, textualidade e materialidade discursiva. In: RODRIGUES, Eduardo Alves; SANTOS, Gabriel Leopoldino dos; BRANCO, Luiza Katia Andrade Castello. (Org.). Análise de discurso no Brasil: pensando o impensado sempre. Uma homenagem a Eni Orlandi. Campinas, Editora RG, 2011, p. 387-400. 